\title{
O QUE HÁ POR TRÁS DAS GRADES: REFLEXÕES SOBRE O TRATAMENTO DAS PRESAS NO CÁRCERE IMPROVISADO DO RN
}

\author{
Lorna Beatriz Negreiros de Araújo ${ }^{1}$
}

RESUMO: O Cárcere no Brasil tem enfrentado dificuldades, juntamente com a situação de crise econômica e política vivida por todo o país. A situação das mulheres presas no Rio Grande do Norte consegue ser ainda pior, em virtude da discriminação por gênero e outras dificuldades peculiares à região. O objetivo desse estudo é refletir sobre como as presas são tratadas no Sistema Prisional Potiguar, principalmente no que concerne ao cumprimento dos Direitos Humanos, tendo em vista as instalações inapropriadas e superlotadas.

Palavras-Chave: Sistema Prisional. Direitos humanos. Mulheres.

\section{INTRODUÇÃO:}

Com o passar dos anos, a sociedade contemporânea foi desenvolvendo-se juntamente com o direito, com o intuito de harmonizar as relações jurídicas e garantir os direitos fundamentais dos seres humanos. No âmbito dessa evolução, é necessário compreender qual o tratamento recebido pelas mulheres encarceradas no Rio Grande do Norte, principalmente no que se refere ao cumprimento dos direitos humanos.

O título "O que há por trás das grades" foi idealizado na intenção de provocar a reflexão sobre o que a Lei, os dispositivos normativos e o Estado não mostram: a realidade vivida na prisão. Apesar de não ter como aprofundar o tema no momento, este é o primeiro passo para um estudo bem mais detalhado futuramente, com o intuito de contribuir com sugestões de melhoria para esta área das políticas públicas.

Assim sendo, através deste pequeno estudo, pretende-se apresentar um breve ensaio sobre a história do cárcere feminino para entender o perfil das mulheres presas na perspectiva nacional, regional e local. Além disso, demonstraremos

\footnotetext{
1 Bacharel em direito pela Universidade Federal Rural do Semiárido, especialista em Direitos Humanos e mestranda em Ciências Sociais e Humanas pela Universidade do Estado do Rio Grande do Norte.
} 
sinteticamente o pensamento de alguns autores sobre como devem ser tratadas essas encarceradas e no último tópico faremos um ensaio sobre a realidade encontrada no Sistema Prisional, para ao final refletirmos de forma crítica sobre os resultados encontrados.

\section{BREVE HISTÓRICO}

A constatação da atividade criminosa das mulheres aconteceu em meados de 1920 quando percebeu-se que, em virtude de necessidade, desequilíbrio psicológico ou até mesmo loucura - por motivos relacionados à influência masculina -, elas se submetiam a atividades delituosas, as quais destaca-se principalmente a prostituição.

O comportamento das apenadas dentro da realidade do crime, como diria LOMBROSO (2014) ao estudar o potencial criminológico e classificar o seu nível de periculosidade no seu livro "The Female Offender", mudou muito. Essa transformação reflete diretamente na realidade que se vive hoje em dia.

Antes, de acordo com o estereótipo patriarcal, a mulher era considerada fruto da docilidade e fragilidade, sendo considerada incapaz de cometer delitos. Por este motivo, o Estado não se preocupava com a situação das mulheres infratoras, tendo em vista o baixo índice de criminalidade por elas cometido (FARIA, 2010).

Entretanto, após os anos 20, a constatação da atividade criminosa das mulheres começou a acontecer quando se percebeu que, em virtude da necessidade, elas se submetiam a atividades delituosas, especialmente a prostituição. Este fato foi observado pelo Estado, quando criou a primeira Penitenciária em 1042, através do Decreto-Lei 3971 de 1941, no Rio de Janeiro (ANDRADE, 2011).

Esse documento legislativo tinha como objetivo principal, dar um tratamento adequado às mulheres, com o intuito de recuperá-las da ilicitude de suas atividades, e separá-las fisicamente dos homens, para a preservação da paz e da ordem no interior do estabelecimento prisional. O objetivo de separação das mulheres com os homens se limitou ao gênero sexual ao qual pertenciam, em virtude da ideia de que a promiscuidade feminina era a maior causadora de criminalidade daquelas mulheres. 
Não houve cuidado em verificar a natureza dos crimes e separar as celas de acordo com a periculosidade. Até meados de 1940, não havia qualquer previsão de Lei ou Decreto para regulamentação, nem existia instituições específicas. Essa realidade só mudou com a chegada do Código Penal em 1940 e do Código de Processo Penal em 1941, respectivamente, quando determinou-se o cumprimento de pena em estabelecimento especial ou, à falta dele, em seção adequada da prisão.

Acontece que, com o tempo, foi percebido que apenas a delimitação de espaço físico específico para separar os gêneros feminino e masculino não era suficiente para fornecer a assistência necessária às mulheres. Depois da implementação dos Códigos, em 1984 foi instituída a Lei de Execução Penal ( $\left.n^{\circ} 7.210 / 84\right)$, que assegurava às mulheres, dentre outros direitos, a conquista do alojamento em celas individuais e salubres, em ambientes próprios e adequados à sua condição pessoal.

Após a chegada das Leis $n^{\circ}$ 11.942/2009 (condições mínimas de assistência) e $n^{\circ} 12.121 / 09$ (segurança interna), dentre as garantias fundamentais fornecidas às mulheres através da LEP, foram implementadas determinações para que os estabelecimentos penais destinados ao público feminino tenham exclusivamente agentes do sexo feminino, sejam dotados de berçário para que elas possam cuidar de seus filhos até os seis meses de idade.

Mais recentemente, em 2014, a Política Nacional de Atenção às Mulheres² determinou que assistência prestada pelo Estado, através dos respectivos órgãos Estaduais de Administração prisional, não deveria ser somente relacionada à estrutura física, mas também material, à saúde, jurídica, educacional, social e religiosa. Além disso, fixou o fornecimento de alimentação, vestuário e instalações higiênicas.

Além das garantias constitucionais, é importante ressaltar os vários Tratados e Convenções Internacionais sobre os Direitos Humanos, dos quais o Brasil é signatário, tais como: a Declaração Universal dos Direitos Humanos - que aborda os direitos pessoais como o direito à igualdade, à vida, à liberdade e à segurança -; a Convenção contra a Tortura e outros Tratamentos Cruéis, Desumanos ou Degradantes; a Convenção Interamericana para Prevenir e Punir a Tortura; a Convenção Interamericana para

\footnotetext{
${ }^{2}$ Brasil. Presidência da República. Política Nacional de Atenção às Mulheres em situação de Privação de Liberdade e Egressas do Sistema Prisional - Brasília: 2014.
} 
Prevenir, Punir e Erradicar a Violência Contra a Mulher (Convenção de Belém do Pará); e a Convenção sobre a Eliminação de todas as Formas de Discriminação Contra a Mulher (CEDAW).

De lá pra cá muitas leis, normas, regulamentos e decretos foram elaborados para implementação de melhorias na efetividade dos direitos humanos no sistema prisional feminino, especialmente com relação à personalização do tratamento feminino de acordo com o gênero, mas conforme veremos a seguir, a realidade continua deplorável.

\section{UM SINGELO OLHAR SOBRE A REALIDADE}

Após o Levantamento Nacional realizado pelo Ministério da Justiça e Segurança Pública em 2016, o INFOPEN, constatou-se que a violação aos direitos humanos e a discriminação por gênero nas Penitenciárias é uma realidade, tendo em vista que as mulheres são vítimas de um sistema carcerário impróprio.

Atualmente, existem 42.355 (quarenta e duas mil, trezentos e cinquenta e cinco) mulheres privadas de liberdade nos estabelecimentos penais que compõem o sistema prisional estadual, tanto nas carceragens quanto em delegacias. Em um contexto internacional, o Brasil compõe a quarta maior população prisional feminina do mundo, perdendo apenas para Estados Unidos, China e Rússia. A pouca quantidade de estabelecimentos prisionais femininos, em contraponto ao crescimento da população carcerária feminina, demonstra a calamidade pública em que vivem as mulheres encarceradas, com um déficit de 13.827 vagas. (INFOPEN, 2018)

Em termos de crescimento carcerário feminino por Região, a Superintendência do Sistema Penitenciário do Brasil, através do INFOPEN 2018, detectou que o Nordeste e o Sul estão empatados com $28 \%$ de aumento na população de mulheres encarceradas. Logo após vem o Norte com 27\%, o Centro-oeste com 9\% e a região Sudeste com $8 \%$ de crescimento carcerário feminino. Quanto ao nível de escolaridade, em média $12 \%$ das mulheres encarceradas não concluíram o ensino médio, a maioria delas (aproximadamente 44\%) não concluiu nem o ensino fundamental, e a taxa de analfabetismo alcança os 5\%. Somente $13 \%$ dessas mulheres 
tem o ensino fundamental completo, $11 \%$ chegaram ao ensino médio e conseguiram concluí-lo e 1\% alcançaram a conclusão do ensino superior (INFOPEN 2018).

Os tipos de delito praticados por mulheres no Brasil se apresentam de forma marcante entre os estados, com maioria (em 60\%) no tráfico. Além desse, 23\% praticam crimes contra o patrimônio, $7 \%$ crimes contra a pessoa, $4 \%$ crime de tráfico internacional, $2 \%$ crimes relacionados a porte ou comércio de arma, e $4 \%$ somam todos os demais crimes. A idade com que essas mulheres praticam os delitos varia entre 18 a 60 anos, com maioria em 26\% dos crimes praticados no período entre 18 e 24 anos, $23 \%$ entre 25 e 29 anos, $18 \%$ entre 30 e 34 anos, $21 \%$ entre 35 e 45 anos, $9 \%$ entre 46 a 60 anos e 1\% com mais de 60 anos (INFOPEN 2018).

No que diz respeito a cor da pele das encarceradas, $45 \%$ delas pertencem à raça parda, $37 \%$ são brancas e $16 \%$ negras. A região Norte é predominada pela raça parda em $74 \%$, enquanto o Sul do País tem maioria de mulheres brancas em $71 \%$. A região Nordeste tem $54 \%$ de mulheres encarceradas da raça parda, no Sudeste o percentual é dividido entre pardos e brancos, e o Centroeste predomina em $60 \%$ os pardos. O maior percentual de negras encarceradas é do Nordeste, com 19\%. Além de tudo isso, $74 \%$ (setenta e quatro por cento) das unidades prisionais habitadas pelas mulheres foram projetadas para homens. (INFOPEN 2018).

As apenadas têm consciência das dificuldades que lhe são impostas pela sociedade, mas muitas vezes consideram isso como castigo merecido (e não uma forma de violência, o que de fato é). Acreditam que a desigualdade social é fruto da ausência de conhecimento, interesse e capacidade. Entendem que os obstáculos impostos à sua educação, bem como oportunidades de emprego melhor, são fatores sintetizados na expressão "foi por falta de opção", que consequentemente as levou a se envolver em atividades ilícitas e ao aprisionamento (SCHERER, 2020).

O Brasil, com o intuito de melhorar o tratamento das mulheres presas, desde o processo de democratização ocorrido com o advento da Constituição Federal de 1988, vem tentando incorporar instrumentos internacionais de proteção aos direitos humanos. Em fevereiro de 1984 a ratificação da Convenção sobre eliminação de discriminação contra a Mulher foi o marco inicial desses eventos (PIOVESAN, 2016). 
Em que pese a tentativa, a chegada da norma institucional e demais legislações de proteção não estão demonstrando eficácia no que toque aos direitos humanos. Comparada a outros estados, a situação do Rio Grande do Norte é caótica, possuindo cerca de 453 mulheres presas (BRASIL, 2018), o que corresponde a um percentual de $6,77 \%$ da população carcerária total. De acordo com o DEPEN, essas mulheres são custodiadas em um estabelecimento prisional (penitenciária), que possui capacidade para 78 presas. Ou seja, o déficit é de 375 vagas.

Essas mulheres presas estão sendo custodiadas de forma improvisada, sem o espaço necessário para exercer atividades laborais e educacionais, em virtude de ter sua liberdade limitada à cela. Também não é possível a permanência de gestantes e de crianças em fase de amamentação, por falta de estrutura. Presença de médicos, enfermeiros ou qualquer profissional da saúde é ainda mais raro. As mulheres estão jogadas às traças, sem visita, sem apoio e sem perspectivas de reinserção na sociedade.

\section{A RELAÇÃO DA MULHER PRESA E A DISCRIMINAÇÃO DE GÊNERO: O QUE DIZEM OS AUTORES?}

Tratar esse tema é de fundamental importância sistêmica na reprodução de injustiças e desigualdades, entretanto a dificuldade no debate é reconhecida por autoras renomadas como Angela Davis, Vilma Reis e Michelle Alexander, que tentam compreender a opressão perpetuada na desigualdade de gênero vivenciada (BORGES, 2019).

Quando a pesquisadora não está no seu "lugar de fala", por ser mulher branca e estar em posição acadêmica privilegiada, é ainda mais complicado tecer comentários pessoais, mas depois de ler o ensaio "corpos negros e as cenas que não vi”3, escrito por inspiração na norteamericana Bell Hooks, percebi a importância de adquirir bases de pesquisa que possa - quem sabe, um dia - denominar interseccional.

No âmbito da criminologia feminina, a atividade da mulher no cárcere tem sido abordada de diferentes formas, sustentada por correntes teóricas que variam entre o positivismo, a crítica e o paradigma do gênero.

\footnotetext{
${ }^{3}$ da autora Camilla de Magalhães Gomes, doutoranda em Direito, Estado e Constituição da UNB. Publicado na revista eletrônica Sistema Penal \& Violência, Porto Alegre, v.8, n.I, p. I6-28., jan-jun. 2016.
} 
Neste último aspecto, conforme visto no título anterior, os dados levantados pelo Departamento Penitenciário Nacional demonstram que a maior parte da população carcerária feminina é parda ou negra. De acordo com o pensamento de Angela Davis (2016), a prisão dessas mulheres é uma continuidade da escravidão, como acontecia desde o sistema colonial, tendo em vista o aparato repressivo e fomentador do racismo.

A mesma autora afirma ainda que, para rever essa situação de discriminação e racismo com as mulheres presas, é necessário buscar alternativas abolicionistas ao cárcere, e não só reformar o sistema prisional na tentativa de encontrar condições menos desumanas.

Esse pensamento é corroborado por Lélia Gonzalez (2011), quando diz que a conscientização da opressão ocorre pelo racial, antes de qualquer outra coisa. A discriminação racial e a exploração de classe constituem elementos básicos da luta comum de mulheres pertencentes a uma etnia subordinada, sendo preponderantes para os estereótipos criados pela sociedade para rotular o perfil da mulher presa.

\section{REFLEXÃO CRÍTICA DOS RESULTADOS E CONSIDERAÇÕES FINAIS}

A história registra verdadeiras barbáries praticadas contra aquele que ocupa a posição do réu no processo penal acusatório, e mesmo quando o Estado assumiu o papel de Órgão Julgador, o incriminado permaneceu ocupando o lugar de "flagelo"." Inúmeros são os exemplos de crueldade com as apenados de forma geral. Podemos citar, primeiramente, os cortes de membros com queima posterior dos restos mortais, mutilações de cabeças seguidas de facadas lançadas ao peito e enforcamento em água quente, além de tantas outras formas de tortura citadas sobre os corpos dos condenados do livro Vigiar e Punir (FOUCAULT, 2001).

No aspecto garantista, Ferrajoli ensina que o modelo acusatório é definido como um sistema processual que tem o juiz como sujeito passivo rigidamente separado das partes, sendo o julgamento fruto de embate que garante (ou ao menos deveria garantir) tratamento igualitário, iniciado pela acusação, à qual compete o ônus da prova, com a participação da defesa, a quem se garante todos os recursos para a ampla defesa,

\footnotetext{
${ }^{4}$ Significado 2. do dicionário Oxford: Punição física, castigo, tortura. 
para que se realize um contraditório público e oral, solucionado pelo juiz com base em sua livre convicção (FERRAJOLI, 2010, p. 520).

Acontece que o enclausuramento normativo trouxe diversos prejuízos às garantias fundamentais dos Direitos Humanos, tendo em vista que a maioria das encarceradas, como demonstra a pesquisa do INFOPEN, é hipossuficiente. Além de todas as dificuldades materiais, ainda são submetidas à deficiências técnicas e formais, por não terem condições de arcar com uma defesa processual técnica e bem fundamentada, especialmente considerando a superlotação de casos e os poucos profissionais disponíveis na defensoria pública, sendo os réus submetidos à defesas genéricas, que trazem prejuízos irreparáveis à vida do acusado.

Fora isso, é evidente que temos uma discrepância gigantesca entre aquilo que é apregoado em nossa Constituição e nossa práxis: basta percebemos que embora nosso modelo penal seja garantista, visando o mínimo possível de regime prisional fechado, sendo o Direito penal a ultima ratio, o que acontece é um encarceramento descomunal que atende ao anseio de punição da população.

Não podemos tratar o direito penal e processual penal apenas por intermédio de uma visão punitiva e legalista, considerando que não prendemos animais, existem variáveis tais como à pessoa, sua remuneração, idade escolar, raça, influência do alcoolismo e drogas.

Faz-se cada vez mais necessária a busca pela superação dessas dificuldades, em virtude do fato de que o ordenamento jurídico, por si só, não é capaz de sanar o problema de desumanização no âmbito do tratamento recebido pelos presos no cárcere.

É imperativo que se promova uma nova política criminal, orientada a reduzir os danos provocados pelo poder punitivo a partir do diálogo inclusivo dos Direitos Humanos, possibilitando uma mudança cultural para que se promova um Controle Constitucional de convencionalidade.

Nesse ínterim, já é possível observar a abertura do Ordenamento Jurídico para as modificações trazidas pelas regras internacionais que se assentam na premissa da defesa dos Direitos Humanos. Como exemplo, podemos citar o julgamento do RE 466.343/SP quando o STF firmou posição de que a Convenção Americana de Direitos 
Humanos $(\mathrm{CADH})$ tem valor supralegal, uma vez que está situada acima das leis ordinárias, mas abaixo da Constituição. Vejamos um trecho:

[...] é possível concluir que, diante da supremacia da Constituição sobre os atos normativos internacionais, a previsão constitucional da prisão civil do depositário infiel (art. $5^{\circ}$, inciso LXVII) não foi revogada pela ratificação do Pacto Internacional dos Direitos Civis e Políticos (art. iI) e da Convenção Americana sobre Direitos Humanos - Pacto de San José da Costa Rica (art. $7^{\circ}, 7$ ), mas deixou de ter aplicabilidade diante do efeito paralisante desses tratados em relação à legislação infraconstitucional que disciplina a matéria, incluídos o art. 1.287 do Código Civil de 1916 e o Decreto-Lei $\mathrm{n}^{\circ}$ 9II, de $\mathrm{I}^{\mathrm{O}}$ de outubro de 1969 . Tendo em vista o caráter supralegal desses diplomas normativos internacionais, a legislação infraconstitucional posterior que com eles seja conflitante também tem sua eficácia paralisada. (BRASIL, 2008).

Apesar do Neoconstitucionalismo ter por base um Estado Democrático de Direito fundado no respeito às garantias fundamentais, a prática desse tema na nossa legislação ainda é muito fragilizada. O legislativo está em constante busca por fontes internacionais que contribuam, em outros aspectos, com a melhor eficácia desses direitos, mas tudo ainda é muito precário e escasso.

Desse modo, é possível afirmar que o Sistema Penal Acusatório nunca foi praticado de forma humanizada, nem na proposta Foucaltiana com o dispositivo disciplinar, muito menos no âmbito do Garantismo Jurídico de Ferrajoli.

Apesar das muitas normas existentes que abordam na teoria a proteção da Dignidade Humana, a prática no tratamento das encarceradas é subjetiva, demonstrando a fragilidade e vulnerabilidade a que são submetidas as acusadas quanto à concretização de seus Direitos Fundamentais.

Os direitos humanos das mulheres encarceradas não estão sendo observados e efetivados de maneira satisfatória. Vivemos em contínuo desrespeito institucionalizado, fato esse que colabora na perpetuação de violação efetiva de princípios humanistas de caráter universal, e, sendo o Estado responsável pelas portas de acesso à justiça penal, é inconteste a falta de compromisso substancial em fazer com que o cidadão adquira espaço de garantia de direitos. Com isso, eleva-se a desigualdade e mitiga-se o sistema garantista.

Inúmeras são as violações aos Direitos Humanos das mulheres presas, o descaso é nítido. A discriminação por gênero também é uma realidade: as mulheres presas estão sendo custodiadas de forma improvisada, sem o espaço necessário para 
exercer atividades laborais e educacionais, em virtude de ter sua liberdade limitada à cela. Também não é possível a permanência de gestantes e de crianças em fase de amamentação, por falta de estrutura.

É fato que os direitos humanos continuam desobedecidos pelos governos, mesmo com os instrumentos normativos que lhes conferem força de lei. Mas a conformidade não é solução pra esse tipo de lacuna. Somando os discursos libertadores com as críticas da sociedade, haverá conversão em práxis ativa da irresignação das minorias (TRINDADE, 2012).

Como afirma Angela Davis, para o feminismo ser relevante, ele precisa ser antirracista e incluir todas as mulheres das mais diversas esferas. Assim sendo, esse estudo representa a inconformação de uma pesquisadora no que toque à desobediência, descaso e irresponsabilidade governamental acerca do tratamento das mulheres presas e à garantia de seus direitos humanos fundamentais.

\section{REFERÊNCIAS}

ANDRADE, Bruna Soares Angotti Batista de. Entre as Leis da Ciência, do Estado e de Deus: o surgimento dos presídios femininos no Brasil (1930-1950). Dissertação de Mestrado em Antropologia Social - Faculdade de Filosofia e Ciências Humanas, Universidade de São Paulo, São Paulo, 2011.

BORGES, Juliana. Encarceramento em massa. Coordenação Djamila Ribeiro. São Paulo: Pólen, 2019.

BRASIL. Supremo Tribunal Federal. Recurso Extraordinário RE 466.343/SP. Disponível em: <http://stf.jus.br/portal/processo/verProcesso Andamento.asp?incidente=2343529>. Acesso em: 14 de julho de 2017 .

BRASIL. Presidência da República. Política Nacional de Atenção às Mulheres em situação de Privação de Liberdade e Egressas do Sistema Prisional - Brasília: 2014.

DAVIS, Angela. Mulheres, raça e classe. $1^{\text {a }}$ ed. São Paulo: Boitempo, 2016. 
FARIA, Thaís Dumêt. Trabalho publicado nos Anais do XIX Encontro Nacional do CONPEDI realizado em Fortaleza-CE, Junho de 2010.

FERRAJOLI, Luigi. Direito e razão, 3. ed. São Paulo: Editora Revista dos Tribunais, 2010 .

FOUCAULT, Michel. Vigiar e Punir: história da violência nas prisões. São Paulo: Vozes, 2001. p. 26.

GONZALES, Lélia. Por um feminismo afro-latino-americano. Caderno de formação política do círculo palmarino - Brasil: 2011.

INFOPEN mulheres - $2^{\mathrm{a}}$ Edição. Organização Thandara Santos: Brasília; Ministério da Justiça e Segurança Pública. Departamento Penitenciário Nacional, 2018.

SCHERER, Zeyne Alves Pires. Mulheres privadas de liberdade: representações sociais de prisão, violência e suas consequências. Revista Brasileira de Enfermagem. Vol 73. Brasília, 2020. Disponível em https://www.scielo.br/scielo.php?script=sci_arttext\&pid=S0034$71672020000300175 \& \operatorname{lng}=e n \& n r m=i s o \& t \operatorname{lng}=p t>$.

TRINDADE, José Damião de Lima. História Social dos Direitos Humanos. São Paulo: Petrópolis, 2012. 